\title{
The relationship between inflammatory markers and disability in chronic obstructive pulmonary disease (COPD)
}

\author{
*Rachel Garroda, Johanna Marshalla, Elizabeth Barley, Salim Fredericksc, Gerry Hagand \\ a School of Physiotherapy, St George's Hospital, University of London, and Kingston University, London, UK \\ ${ }^{b}$ Institute of Psychiatry, London, UK \\ ' Cardiac and Vascular Sciences, St George's Hospital, University of London, UK \\ ${ }^{\mathrm{d}}$ Research and Development section, GlaxoSmithKline.
}

Received 26th October 2006; accepted 26th March 2007

\begin{abstract}
Aims: To examine relationships between markers of systemic inflammation and functional status in patients with chronic obstructive pulmonary disease (COPD).

Methods: 41 COPD patients were stratified using the Medical Research Council (MRC) dyspnoea scale. Six-minute walking distance (6MWD), Quadriceps (\% body weight) (QBW), St George's Hospital Respiratory Questionnaire (SGRQ), London Chest Activity of Daily Living Scale (LCADL), C-reactive protein (CRP), interleukin 6 (IL6), tumour necrosis factor $\alpha$, and neopterin were measured. Relationships between variables and differences in inflammatory markers between MRC categories were tested.

Results: Inflammation increased with MRC grade and was significantly different across grades; CRP ( $p=0.002)$ and IL6 ( $p=0.04)$. Relationships were evident between CRP, 6MWD, LCADL and SGRQ, $r=-0.47,0.50,0.43$ (all $p<0.01$ ) respectively, and between IL6, QBW and LCADL, rho=-0.36, $0.51(p<0.05)$.

Conclusions: Measures of systemic inflammation, and in particular CRP, may prove to be useful markers in the assessment of COPD severity in primary care.

(c) 2007 General Practice Airways Group. All rights reserved.

R Garrod, et al. Prim Care Resp J 2007; 16(4): 236-240.

doi:10.3132/pcrj.2007.00047
\end{abstract}

Keyw ords COPD, CRP, inflammatory markers, exercise, disability, breathlessness

\section{Introduction}

Patients with chronic obstructive pulmonary disease (COPD) have impaired functional status. ${ }^{1-3}$ Quality of life and exercise tolerance provide comprehensive information about the patient and there is evidence that frequency of exacerbation is associated with health status impairment. ${ }^{4}$ The degree of breathlessness using the Medical Research Council (MRC) dyspnoea scale has been identified as a stronger predictor of 5 -year mortality than the forced expiratory volume in one second $\left(\mathrm{FEV}_{1}\right){ }^{5}$ and measures of health status and exercise tolerance are strongly associated with mortality. ${ }^{6}$ However, severity of COPD is most often assessed using measures of lung function - usually $\mathrm{FEV}_{1}$ - although functional status in $\mathrm{COPD}$ bears little or no relationship with $\mathrm{FEV}_{1} .{ }^{7}$ In the primary care management of COPD, assessment of exercise tolerance and health status may prove unrealistic, thereby highlighting a need for simple biomarkers of severity.

COPD is a multi-component disease with known systemic effects such as cachexia, reduced muscle mass, and osteoporosis. ${ }^{8}$ Concentrations of inflammatory markers such as C-reactive protein (CRP), interleukin 6 (IL6) and tumour necrosis factor (TNF- $\alpha$ ) are higher in COPD patients compared with healthy individuals,10 and CRP is an independent prognostic variable for heart disease. ${ }^{11}$ Neopterin is highly prognostic of major adverse coronary events in angina ${ }^{12}$ and is recognised as a risk factor for acute respiratory tract infections in COPD patients. ${ }^{13}$ There has been recent work on the contribution of chronic low grade inflammation to impairment in health status and disability; COPD patients with raised CRP have worse quality of life, exercise capacity and

\footnotetext{
* Corresponding author: School of Physiotherapy, 2nd Floor, Grosvenor Wing, St George's Hospital, University of London, Cranmer Terrace, Tooting, London, SW17 ORE, UK. Tel: +44 (0)208 7250377 Fax: +44 (0)208 7252248 Email: garrod@hscs.sgul.ac.uk
} 
lung function..$^{10,14,15}$ Over the past decade there has been much progress in understanding factors that contribute to disability and exacerbation in COPD. Muscle weakness has been accepted as an important feature of impaired activity ${ }^{16}$ and the influence of systemic inflammation on cachexia and muscle wasting has been described. ${ }^{17}$ However, before measures of inflammation can confidently be utilised in the primary care assessment of COPD, further work is required to identify possible relationships with other validated measures and to explore differences according to perceived disability.

The aim of this study therefore was to examine relationships between known markers of inflammation - CRP, TNF- $\alpha$, IL6 and neopterin - and measures of disability and handicap in COPD patients. An additional aim was to consider differences in inflammation after stratification using the MRC dyspnoea scale.

\section{Methods}

Patients with a diagnosis of COPD confirmed by spirometry ${ }^{18}$ were recruited from secondary and primary care services. Patients had stable COPD (no change in medical intervention over the last four weeks) and were excluded if they had unstable angina, intermittent claudication, mobility-limiting conditions, previous stroke, cognitive impairment, or comorbidity of an inflammatory nature e.g. rheumatoid arthritis. The study protocol was approved by the Merton Sutton and Wandsworth Research Ethics Committees and conducted according to Good Clinical Practice Guidelines and the 1996 declaration of Helsinki. Signed informed consent was obtained from all patients. Patients attended hospital twice and assessments were performed in the following order.

\section{Visit 1}

Body mass index (BMI): Weight, with clothes on, and height, minus shoes was measured. BMI was calculated as weight $(\mathrm{kg}$ ) divided by height $(\mathrm{m})$ squared.

Smoking status: was measured in pack years.

Systemic inflammation: CRP, IL6, TNF- $\alpha$, Neopterin: venous blood was taken at the initial visit, at rest prior to all other tests. Plasma was frozen at $-80^{\circ} \mathrm{C}$ within an hour of sampling. High sensitivity CRP, IL6 and TNF- $\alpha$ were all measured using commercially available assays (Euro/DPC Ltd, Gwynedd, UK) and performed on an Immulite ${ }^{\circledast}$ automated analyser (Euro/DPC Ltd). The functional sensitivities of each of the assays were $0.2 \mathrm{mg} / \mathrm{l}, 2.0 \mathrm{ng} / \mathrm{l}$, and $1.7 \mathrm{ng} / \mathrm{l}$ for CRP, IL6 and TNF- $\alpha$ respectively. Serum neopterin (nmol/l) was analysed using an enzyme-linked Immunosorbent Assay (ELISA), in accordance with the manufacturers' instructions (Brahms, Henningsdorf, Germany).

Health-related quality of life was assessed using the St George's Hospital Respiratory Questionnaire (SGRQ). ${ }^{19}$ Scores are expressed as a percentage of overall impairment where 100 represents poorer health status and 0 indicates best possible health status.

Breathlessness during daily activities was assessed using The London Chest Activity of Daily Living Scale (LCADL), a 15-item questionnaire designed to measure dyspnoea during routine daily activities in patients with COPD. Patients score from 0 to 5 with higher scores representing maximal disability. ${ }^{20}$

Subjective breathlessness. The MRC Dyspnoea Scale ${ }^{21}$ was used to divide patients into groups according to their level of perceived breathlessness. Three groups were used: MRC grades $1 \& 2$ - those who were "troubled by breathlessness on strenuous exertion" or "short of breath when hurrying"; MRC grades $3 \& 4$ - patients who needed to "walk slower than most people (of my own age) on the level" or to "stop for breath after walking about one hundred yards on the level"; and MRC Grade 5 - those who were "too breathless to leave the house" or were "breathless after undressing ".

Exercise capacity was assessed using the six-minute walking distance (6MWD) according to ATS instructions and along a 30 metre corridor. ${ }^{22}$ Results were recorded as actual values and as percent predicted of normal data. ${ }^{23}$

\section{Visit 2 - other measures of disease}

Lung function: FEV 1 and forced vital capacity (FVC) were measured using "SensorMedics TM Vmax 29c Cardiopulmonary Exercise Testing Instrument," in accordance with the manufacturer's and BTS instructions. ${ }^{18}$

Peak exercise tolerance: $\mathrm{VO}_{2}$ peak $(\mathrm{ml} / \mathrm{kg} / \mathrm{min})$ was measured using Vmax 29c equipment according to the Naughton protocol. ${ }^{24}$ The test was stopped either when patients were unable to tolerate symptoms any longer or when anaerobic threshold point was detected.

Muscle strength: quadriceps muscle strength was assessed using a "Cybex Norm ${ }^{\mathrm{TM}}$ Testing and Rehabilitation System" in accordance with manufacturers instructions. Maximum torque was recorded as percentage of body weight (Quads \% pred). Grip strength was measured using a "Baseline ${ }^{\mathrm{TM}}$ Hydraulic Hand Dynamometer". The best of three attempts was recorded as \% of reference values. ${ }^{25}$

Maximal Inspiratory (MIP) and Maximal Expiratory (MEP) Pressures: these were measured using Jaeger Masterscreen Body ${ }^{\mathrm{TM}}$ equipment. The best of three attempts for both MIP and MEP ( $\mathrm{cm} \mathrm{H2O}$ ) were recorded. ${ }^{26}$

\section{Statistical analysis}

Log transformation was necessary to achieve a normal distribution for CRP and neopterin, but this could not be achieved for IL6 and TNF- $\alpha$. All other variables were normally distributed. Differences between MRC breathlessness categories were examined using Analysis of Variance (ANOVA). Post hoc tests were performed. Correlations between measures of functional status, measures of systemic 
Table 1. Median (range) cytokine levels in total group and according to MRC Dyspnoea Grade.

\begin{tabular}{llllll} 
MRC Dyspnoea Grade & $\mathrm{N}$ & Neopterin $(\mathrm{n} / \mathrm{mol} / \mathrm{l})$ & TNF- $\alpha(\mathrm{pg} / \mathrm{ml})$ & CRP (mg/l) & IL6 (pg/ml) \\
\hline MRC 1 \& 2 & 10 & $5.1(7.5)$ & $10.2(27.9)$ & $2.6(5.9) * *$ & $1.9(2.3) *$ \\
MRC 3 \& 4 & 21 & $6.3(8.6)$ & $15.7(27.1)$ & $6.8(32.7)$ & $3.6(28.7)$ \\
MRC 5 & 10 & $7.1(11.1)$ & $19.5(28.1)$ & $7.2(16.4) * *$ & $3.6(8.2) *$ \\
\hline
\end{tabular}

MRC = medical research council; TNF- $\alpha=$ tumour necrosis factor alpha; CRP = C-reactive protein; IL6 = Interleukin 6

** Difference between groups at $p=0.01$; Difference between groups at $p=0.04$

Table 2. Relationships between systemic inflammation and functional and other measures of disease.

\begin{tabular}{lllll} 
& CRP $(\log 10)$ & Neopterin $(\log 10)$ & IL6 & TNF- $\alpha$ \\
\hline Quads \% BW & $-0.34^{*}$ & -0.12 & $-0.36^{*}$ & -0.10 \\
SGRQ Tot & $0.43^{* *}$ & 0.12 & 0.27 & 0.16 \\
VO2 peak & $-0.46^{* *}$ & $-0.37^{*}$ & -0.31 & 0.11 \\
6MWD (m) & $-0.47^{* *}$ & $-0.33^{*}$ & 0.10 & 0.10 \\
6MWD \% pred & $-0.46^{* *}$ & -0.29 & $-0.36^{*}$ & -0.01 \\
LCADL & $0.50^{* *}$ & $0.32^{*}$ & $0.51^{* *}$ & 0.18 \\
age & 0.27 & $0.43^{* *}$ & $0.34^{*}$ & 0.13 \\
BMI & 0.20 & 0.01 & 0.13 & -0.11 \\
pack years & 0.18 & -0.003 & 0.19 & 0.22 \\
FEV $\%$ pred & -0.16 & 0.22 & 0.16 & 0.19 \\
FEV1 (I) & $-0.33 *$ & -0.08 & -0.22 & 0.17 \\
Grip \% pred & -0.26 & $-0.34^{*}$ & -0.18 & 0.05 \\
MIP \% pred & -0.27 & 0.11 & -0.21 & -0.03 \\
MEP \% pred & -0.16 & 0.04 & 0.04 & 0.16 \\
\hline
\end{tabular}

SGRQ Tot $=$ St George's Respiratory Questionnaire Total. 6MWD = 6 Minute walking Distance (\% pred of normal values).

$\mathrm{LCADL}=$ London Chest Activity of Daily Living, $\mathrm{VO}_{2}$ peak = peak oxygen consumption, Quads \% BW quadriceps strength \% body weight.

$\mathrm{BMI}=$ Body Mass Index. $\mathrm{FEV}_{1} \%$ pred $=$ Forced Expiratory Volume in one second $\%$ pred. $\mathrm{VO}_{2}$ peak = peak oxygen consumption.

Quads \% BW quadriceps strength \% body weight; MIP = maximal inspiratory pressure; MEP = maximal expiratory pressure \% predicted.

${ }^{* *}=p<0.01 ;{ }^{*}=p<0.05$

inflammation and the other measures of disease were calculated using Pearson's $r$ and Spearman's rho. For all tests $\mathrm{p}<0.05$ was taken as significant. One outlier was removed from the data set as this individual had a CRP level $>70 \mathrm{mg} / \mathrm{l}$ and was likely to be experiencing an exacerbation. Analysis was carried out using SPSS version 12

\section{Results}

\section{Demography}

Forty-three COPD patients were recruited (21 male). Mean $\mathrm{FEV}_{1}$ (SD) was 1.13 (0.5)l, mean age (range) was 68.3 (44 88 ) years, and smoking history expressed as mean (SD) pack years was 41.6 (34.8). One patient declined to have his blood taken, leaving 42 samples for analysis. As previously mentioned, one outlier with an initial high CRP level was removed. Ten patients described themselves as MRC Grades 1 or 2, 21 as MRC Grades 3 or 4, and 10 as MRC Grade 5. Sixminute walking distance (6MWD) expressed as \% predicted was low with a mean (SD) value of $48.0(22.5) \%$. Health status was impaired; mean (SD) SGRQ Total was 71.0 (19.2). Co-morbidity was low in this group; six patients were hypertensive and five had type 2 diabetes. Oral corticosteroids were not being prescribed for any patient.

\section{Relationships between MRC breathlessness and systemic inflammation}

Values of systemic inflammation increased with 
breathlessness level for all markers. Differences between the groups were significant for CRP (ANOVA, $p=0.002$ ) and IL6 (Kruskall Wallis, $p=0.04$ ). Post hoc tests showed that the differences were between Grades $1 \& 2$ and Grade 5 patients (Table 1).

\section{Relationships between systemic inflammation, measures of functional status, and other measures of disease}

CRP and TNF- $\alpha$ were both correlated with IL6 (rho $=0.61, p<$ $0.0001 \&$ rho $=0.34, p=0.03$ respectively). Correlations between the inflammatory markers - CRP, TNF- $\alpha$, IL6, neopterin - and the other measures of disease are shown in Table 2.

\section{Discussion}

This study, like others published recently, ${ }^{10}$ confirms that measures of chronic low-grade inflammation in patients with stable COPD are associated with measures of exercise tolerance and health status. Furthermore, severity - as assessed by $\mathrm{FEV}_{1}$ - was not predictive of systemic inflammation whereas inflammatory markers were higher across all levels of breathlessness. It is of note that even in our MRC Dyspnoea Grades 1 \& 2 patients (with a mean FEV 1 of $62 \%$ predicted) median CRP levels were close to $3 \mathrm{pg} / \mathrm{m}$, a level considered significantly to increase cardiovascular disease in otherwise healthy women. ${ }^{11}$ Therefore, our data, as well as other data, ${ }^{27}$ suggest that inflammation may occur earlier in COPD than previously recognised.

A new finding from our data is the evidence of a relationship between neopterin and grip strength. Whilst we recognise the possibility of type I error, we highlight this as an important area for future research. This relationship is supported by other data showing grip strength as a predictor of mortality after pneumonia ${ }^{28}$ and neopterin as a risk factor for respiratory tract infection ${ }^{13}$ and cardiovascular events. ${ }^{12}$ These observations may have clinical implications when assessing COPD severity and exacerbation in primary care.

We found that quadriceps muscle strength, but not respiratory nor grip strength, was associated with systemic levels of CRP, and IL6. In addition, the negative relationship between IL6 and walking distance has resonance with one study in which infusion of recombinant IL6 was found to increase fatigue and impair exercise performance in athletes. ${ }^{29}$ Systemic inflammation may play a contributory role in the development of peripheral muscle fatigue and in the perception of fatigue in COPD. In primary care the assessment of inflammation may complement management and highlight the need for other therapeutic interventions such as pulmonary rehabilitation.

This preliminary study is not designed to elicit mechanisms nor conclude the source of these raised inflammatory markers. Possible sources include; pulmonary, epithelial cells, muscle, or hepatic, or an interaction between all these potential sources. Up-regulation of hepatic increased levels of systemic IL6 from a pulmonary source, such as fibroblasts, could mediate CRP. Chronic low-grade systemic inflammation may then affect muscle strength through a number of processes - in particular, inactivity, oxidative stress, lactic acidosis and inflammatory cytokines working congruently to disrupt the local anabolic/catabolic mechanisms in play. ${ }^{17}$ Our study was not able to demonstrate an association between serum TNF- $\alpha$ and measures of disability or health status. It is possible that different results would have been observed had we focussed on TNF receptors rather than serum markers, as suggested by data from Broekhuizen and colleagues. ${ }^{10}$

In summary, relationships between CRP, IL6 and healthrelated quality of life confirm the importance of systemic inflammation in patient perceptions of the impact and symptoms of COPD. CRP levels are higher in those patients with greater perception of breathlessness during mobilisation. Recent data show that CRP is an important predictor of future exacerbation and hospitalisation; ${ }^{30}$ we suggest that measures of inflammation may prove useful in the comprehensive assessment and follow up of COPD patients in primary care.

\section{Funding}

This study was funded by The Health Foundation and GlaxoSmithKline (GSK) Research and Development.

\section{Conflict of interest statement}

Rachel Garrod has worked as a consultant for GSK and Boehringer/Pfizer, and gives talks for both companies. She has received funding from GSK up to $£ 60,000$.

G Hagan is employed by GSK.

All other authors have no conflicts of interest.

\section{References}

1. Bestall JC, Paul EA, Garrod R, Garnham R, Jones PW, Wedzicha JA. Usefulness of the Medical Research Council (MRC) dyspnoea scale as a measure of disability in patients with chronic obstructive pulmonary disease. Thorax 1999; 54(7):581-6.

2. Moody L, McCormick K, Williams A. Disease and symptom severity, functional status, and quality of life in chronic bronchitis and emphysema (CBE). J Behav Med 1990;13(3):297-306.

3. Schlecht NF, Schwartzman K, Bourbeau J. Dyspnea as clinical indicator in patients with chronic obstructive pulmonary disease. Chron Respir Dis 2005; 2(4):183-91.

4. Seemungal TA, Donaldson GC, Paul EA, Bestall JC, Jeffries DJ, Wedzicha JA. Effect of exacerbation on quality of life in patients with chronic obstructive pulmonary disease. Am J Respir Crit Care Med 1998;157(5 Pt 1):1418-22.

5. Nishimura K, Izumi T, Tsukino M, Oga T. Dyspnea is a better predictor of 5-year survival than airway obstruction in patients with COPD. Chest 2002; 121(5):1434-40.

6. Oga T, Nishimura K, Tsukino M, Sato S, Hajiro T. Analysis of the factors related to mortality in chronic obstructive pulmonary disease: role of exercise capacity and health status. Am J Respir Crit Care Med 2003;167(4):544-9.

7. Jones PW. Health status measurement in chronic obstructive pulmonary 
disease. Thorax 2001; 56(11):880-7

8. Agusti AG. COPD, a multicomponent disease: implications for management. Respir Med 2005;99(6):670-82.

9. Gan WQ, Man SF, Senthilselvan A, Sin DD. Association between chronic obstructive pulmonary disease and systemic inflammation: a systematic review and a meta-analysis. Thorax 2004;59(7):574-80.

10. Broekhuizen R, Wouters EF, Creutzberg EC, Schols AM. Raised CRP levels mark metabolic and functional impairment in advanced COPD. Thorax 2006; 61(1):17-22

11. Ridker PM, Hennekens $\mathrm{CH}$, Buring JE, Rifai N. C-reactive protein and other markers of inflammation in the prediction of cardiovascular disease in women. N Engl J Med 2000;342(12):836-43.

12. Avanzas P, Arroyo-Espliguero R, Cosin-Sales J, et al. Markers of inflammation and multiple complex stenoses (pancoronary plaque vulnerability) in patients with non-ST segment elevation acute coronary syndromes. Heart 2004;90(8):847-52.

13. Takabatake N, Sata M, Abe S, et al. Impaired systemic cell-mediated immunity and increased susceptibility to acute respiratory tract infections in patients with COPD. Respir Med 2005;99(4):485-92.

14. de Torres JP, Cordoba-Lanus E, Lopez-Aguilar C, et al. C-reactive protein levels and clinically important predictive outcomes in stable COPD patients. Eur Respir J 2006;27:902-07

15. Rabinovich $R$, Figueras $M$, Ardite $E$, et al. Increased tumour necrosis factor alpha plasma levels during moderate-intensity exercise in COPD patients. Eur Respir J 2003;21:789-94.

16. Bernard S, Leblanc P, Whittom F, Carrier G, Jobin J, Belleau R, Maltais F. Peripheral muscle weakness in patients with chronic obstructive pulmonary disease. Am J Respir Crit Care Med 1998;158(2):629-34.

17. Debigare $\mathrm{R}$, Cote $\mathrm{CH}$, Maltais $\mathrm{F}$. Peripheral muscle wasting in chronic obstructive pulmonary disease. Clinical relevance and mechanisms. Am J Respir Crit Care Med 2001;164(9):1712-17.

18. British Thoracic Society. BTS guidelines for the management of chronic obstructive pulmonary disease. The COPD Guidelines Group of the Standards of Care Committee of the BTS. Thorax 1997; 52(Suppl 5):S1-28.

19. Jones PW, Quirk FH, Baveystock CM, Littlejohns P. A self-complete measure of health status for chronic airflow limitation. The St. George's Respiratory Questionnaire. Am Rev Respir Dis 1992;145(6):1321-7.

20. Garrod R, Paul EA, Wedzicha JA. An evaluation of the reliability and sensitivity of the London Chest activity of Daily Living Scale (LCADL). Respir Med 2002:96:725-30.

21. Burdon JG, Juniper EF, Killian KJ, Hargreave FE, Campbell EJ. The perception of breathlessness in asthma. Am Rev Respir Dis 1982;126(5):825-8.

22. ATS Statement: Guidelines for the Six-Minute Walk Test. Am J Respir Crit Care Med 2002:166(1):111-17

23. Enright $\mathrm{PL}$, Sherrill $\mathrm{DL}$. Reference equations for the six-minute walk in healthy adults. Am J Respir Crit Care Med 1998;158(5 Pt 1):1384-7.

24. Naughton J, Sevelius G, Balke B. Physiological responses of normal and pathological subjects to a modified work capacity test. J Sports Med Phys Fitness 1963:44:201-07.

25. Mathiowetz V, Kashman N, Volland G, Weber K, Dowe M, Rogers S. Grip and pinch strength: normative data for adults. Arch Phys Med Rehabil 1985, 66(2):69-74

26. Black LF, Hyatt RE. Maximal respiratory pressures: normal values and relationship to age and sex. Am Rev Respir Dis 1969:99(5):696-702.

27. Hogg JC, Chu F, Utokaparch S, et al. The nature of small-airway obstruction in chronic obstructive pulmonary disease. N Engl J Med 2004;350(26):2645-53.

28. Bohannon RW, Maljanian R, Ferullo J. Mortality and readmission of the elderly one year after hospitalization for pneumonia. Aging Clin Exp Res 2004; 16(1):22-5.

29. Robson-Ansley PJ, de Milander L, Collins M, Noakes TD. Acute interleukin- 6 administration impairs athletic performance in healthy, trained male runners. Can J Appl Physiol 2004;29(4):411-18.

30. Dahl M, Vestbo J, Lange P, Bojese SE, Tybjaerg-Hansen A, Nordestgaard BG. Creactive Protein as a Predictor of Prognosis in COPD. Am J Respir Crit Care Med 2007; 175:250-5. doi:10.1164/rccm.200605-7130C

\section{Available online at http://w w w.thepcrj.org}

